\title{
The BOPPPS Teaching Mode in the Reform of Nursing English
}

\section{YANG Di}

\author{
School of Foreign Language, Hubei University of Chinese Medicine, Wuhan 430065, China.
}

Keywords: BOPPPS teaching mode; nursing English teaching; teaching mode reform

\begin{abstract}
The traditional teaching mode adopted in nursing English teaching can no longer meet the needs of modern nursing English teaching. The traditional teaching model should be replaced by a new teaching model. This paper explores the limitations of the traditional teaching model and proposes a new method to solve the problem by adopting the BOPPPS teaching model in the teaching reform. This paper also demonstrates the teaching mode of BOPPPS, which covers all the links of the whole teaching process and provides new theoretical guidance and teaching methods for teachers. The purpose of this study is to illustrate the new teaching mode, which can indeed improve students' participation in the classroom and promote effective learning.
\end{abstract}

\section{Introduction}

The emergence of the international medical market has promoted the international flow of nurses. At the same time, the rapid development of medical and health services in China has also prompted the demand for international nursing professionals with rich professional knowledge and practical experience. Such opportunities and challenges put forward higher requirements for the training of foreign nursing personnel in China. Nursing English education in the new century must be reformed and innovated, a training mode of nursing talents should be established to meet the international development trend, and modern nursing talents with broad knowledge, solid foundation, strong comprehensive ability, high clinical quality and innovative spirit should be trained.

The major of foreign-related nursing is to train international foreign-related nursing talents with certain basic medical knowledge and nursing professional skills, who are proficient in English listening, speaking, reading and writing and are familiar with the culture of English-speaking countries. [1] Therefore, nursing English is a compulsory course for foreign nursing students, a core course to cultivate students' professional English ability, and a key course to help students pass the national medical English proficiency test [2].

However, the teaching of nursing English in China focuses on the teaching of linguistic theory and basic nursing skills. Although students have basic knowledge and nursing skills imitative ability, their abilities of independent learning, language clinical application, teamwork and learning innovation are relatively weak. Indeed, there are still some problems in the process of nursing English teaching, such as imperfect teaching system, unclear teaching purpose, weak teachers and lack of teaching materials. In order to overcome these problems, it is urgent to establish a more reasonable and sound teaching system of foreign-related nursing English, implement effective teaching mode reform to promote the improvement of teachers' teaching level, in order to cultivate international nursing talents which are really suitable for the needs of the society.

This paper aims to study the reform of nursing English Teaching under the guidance of BOPPPS teaching mode [3]. The teaching philosophy of higher education is to carry out the teaching process centered on the students, so as to achieve the teaching purpose of the students to master the knowledge they have learned. The BOPPPS teaching mode is to establish the main position of students in the teaching, to emphasize the participatory learning of teachers and students, to meet the requirements of teaching purposes. It also has obvious advantages in mobilizing students' subjective initiative, improving comprehensive analysis ability and innovative scientific research ability. Similarly, this teaching model has important reference value for the reform of English for foreign-related nursing in colleges and universities. It is very suitable for nursing English teaching. 


\section{The Current Situation of Foreign-Related Nursing English Teaching}

\subsection{The teaching system is imperfect and the teaching objectives are not clear}

At present, many colleges and universities still follow the traditional mode of College English curriculum, and have not formulated the syllabus and teaching objectives for the specialty of foreign-related nursing. For a long time, English teaching has focused on the interpretation and understanding of language rules, emphasized the repetition of sentence patterns, and neglected the students' language training and practice in the actual situation [4]. In the actual teaching, because of the backward teaching equipment and the lack of scene teaching conditions of foreign-related nursing, students cannot complete the study of professional English by simulating or in the real working situation. The traditional college English teaching mode restricts the development of nursing English teaching activities to a large extent, hinders the improvement of students' practical use of English, and does not meet the actual needs of foreign-related nursing professionals.

\subsection{Urgent need to strengthen the training of teachers}

Nursing English teaching requires teachers to have rich medical and nursing professional knowledge and high level of English language ability. However, there is a widespread situation in Colleges and universities: English teachers lack relevant medical and nursing professional knowledge, and focus on English language teaching in the teaching process and cannot be combined with the theoretical knowledge of nursing profession. Teachers with a wealth of medical and nursing expertise have a slightly insufficient level of English and lack the methods and skills of language teaching. Therefore, if the teacher's "bilingual" ability is not enough, it will inevitably affect the teaching effect and fail to achieve the expected teaching effect.

The orientation of English curriculum in Colleges and universities still tends to be based on the teaching of basic knowledge. In terms of teaching content, professional English cannot be integrated into it. It always focuses on vocabulary explanation, grammar analysis and text translation. Students' passive learning neglects the guidance of professional English oriented by working process, which leads to the students' simple mastery of English knowledge or syntactic structure. Even if they have been learning English for a long time, they still cannot use English in medical care.

\subsection{Lack of excellent professional teaching materials}

At present, the teaching materials for professional English in the market are far less than those for public English, and there are few authoritative textbooks that are widely recognized. The content of professional textbooks is lack of diversity,, targeted is not strong, and the difficulty is far beyond the scope of students' ability, which is not conducive to the cultivation of students' English language communication ability. However, a small number of nursing professional English textbooks tend to cultivate students' ability to read medical literature and expand students' medical English vocabulary. Some textbooks focus on the scope of medical English and are not closely related to nursing expertise. Moreover, there is a serious shortage of English video materials and listening materials for students to perform audiovisual training. Therefore, one of the problems faced in the teaching of nursing professional English is the lack of targeted and systematic teaching materials.

\section{Reform of nursing English Teaching Mode}

\subsection{Reforming the existing teaching model and clarifying the teaching objectives}

The establishment of foreign-related nursing specialty is to cultivate international nursing talents with strong English listening, speaking, reading and writing ability to meet the needs of international nursing objects, and must have professional medical and nursing basic theoretical knowledge and practical skills of high-quality. Therefore, the teaching objectives of foreign-related nursing English should be as follows: while teaching medical and nursing theoretical knowledge, cultivating students' comprehensive English application ability, paying attention to the cultivation of students' intercultural communication ability, strengthening students' oral communication ability, and guiding students to master a certain amount of professional English vocabulary; improve students' clinical English usage in nursing. 
Under the guidance of clear teaching objectives, the traditional teaching model should be adjusted. It is necessary to strengthen English teaching and focus on cultivating students' ability to use English in the professional field. Increase the proportion of practical courses, English teaching in nursing medicine scenes, in practice to train students' oral communication ability [5]. The communicative teaching method of "student-centered" should be carried out with various teaching methods to stimulate students' interest in learning. The key point of nursing foreign-related English teaching is to combine the ability of oral English with the professional skills of medical nursing so as to cultivate skilled and practical high-quality compound talents. Starting from the reality of foreign-related nursing English teaching, we explore the educational mode of "teaching and learning" optimized combination, and gradually form a complete teaching system with foreign-related professional characteristics.

\subsection{Enhance professional communication and strengthen teacher training}

Based on the characteristics and needs of foreign-related nursing teaching, a sustainable training program was formulated to provide follow-up education for teachers. Organize nursing teachers to carry out English training and improve their English level. Or to train English teachers in medical and nursing professional knowledge so that they can master the necessary theoretical knowledge of nursing profession and improve their comprehensive teaching ability. At the same time, a team of nursing teachers and English teachers should be formed to study and discuss together and make teaching plan courseware collectively so as to improve teaching quality and cultivate qualified foreign nursing talents.

In order to deepen students' understanding of foreign nursing work and foreign medical system and broaden their employment vision, universities should regularly invite foreign nursing experts to hold series of lectures on foreign-related nursing knowledge, or invite foreign teachers to participate in nursing professional teaching and management to further integrate nursing education with international standards.

\subsection{Conducting research and compilation of textbooks}

Textbooks are the knowledge carrier of teaching content, the basic basis of teaching activities, and the key factor to determine the teaching efficiency and quality. Since the existing textbooks cannot meet the teaching needs of nursing English, professional teachers should be encouraged and supported to develop and compile nursing English textbooks adapted to the actual level and professional needs of students. At present, the content of professional textbooks is lack of diversity, audio-visual materials, targeted is not strong, and the difficulty is far beyond the scope of students' ability, which is not conducive to the cultivation of students' English language communication ability.

In the process of compiling the textbook, on the basis of systematic introduction of nursing theory and medical knowledge, classify each medical department according to the nursing work, the specific content of the textbook should be determined by the task flow in the actual nursing work. The textbook should provide comprehensive nursing English training for students in four aspects: listening, speaking, reading and writing. It can help students lay a solid foundation of nursing knowledge, in order to improve students' comprehensive use of clinical English[6].

\section{Reform Teaching Mode}

\subsection{Traditional teaching mode and BOPPPS teaching mode}

At present, nursing English in our country adopts the traditional language teaching mode, which emphasizes on the teaching of English language and cannot be combined with the theoretical knowledge of nursing specialty. In the traditional teaching process, the participation of students is not high, only playing the role of "listeners". The students rely on the electronic courseware of the teacher's lecture, neglect to take notes, unable to really understand and master the knowledge points. At the same time, at the end of a class, teachers cannot get students' feedback information in time, do not know students' knowledge acceptance and needs in class, and cannot adjust the teaching content according to students' feedback immediately.

In recent years, the BOPPPS teaching mode has been more and more appreciated and respected by many universities. BOPPPS teaching mode divides the whole teaching process into six stages: bridge in, 
learning objective, pre-test, participatory learning, post-assessment and summary. The core of BOPPPS teaching mode is to pay attention to students' development needs, regard students as teaching center, pay attention to students' learning participation ability and give feedback to students' learning results. The ultimate goal of teaching is to make students fully grasp the knowledge and make them have the ability to use it. The teaching model based on BOPPPS theory conforms to the trend of English teaching reform for nursing specialty and can combine English learning with medical and nursing knowledge. It can promote students to participate in all aspects of learning. Through discussion, induction, practice, review and summary of teaching content, students' practical ability, learning ability can be truly cultivated and the best learning effect can be achieved.

\subsection{Adoption of BOPPPS teaching mode}

In the process of teaching, teachers should adopt a variety of teaching methods, combining blackboard writing, PPT courseware, pictures, video playback, and can make corresponding adjustments according to students' feedback. Changing the traditional teacher centered teaching mode and truly "student centered". Develop students' learning potential to the greatest extent and stimulate students' enthusiasm for learning so as to achieve the goal of teaching.

Teachers first consider how to design an effective "bridge-in", effective introduction to ensure that students and learning content in some form of association. This kind of association can increase students' input and attention in pre-class learning, and help students complete learning tasks more efficiently. In the "bridge in" (introduction) section of the BOPPPS teaching mode, because the students' pre-study makes the learning content no stranger, the teacher's teaching is smoother. In the teaching process, let students carry out reading training on the basis of accumulating a certain amount of vocabulary, which will certainly enhance students' ability to understand and analyze the article.

Medical English vocabulary is the key to learn nursing English well. However, medical vocabulary has three sources: English, Latin and Greek. These vocabularies are characterized by complicated word formation. The complexity and particularity of these words bring great difficulties to students' learning. Teachers can summarize the characteristics and difficulties of medical vocabulary, adopt a gradual teaching method, through the "root, prefix, suffix" morphology teaching, to help students find the rules of memory, to overcome the difficulties of professional vocabulary learning. In the "pre-test" part of the BOPPPS teaching mode, the medical vocabulary and thinking questions are listed in advance before the class, so that students can prepare in advance by means of self-learning, and have a general understanding of the content of the text to be learned.

The "student-centered" teaching BOPPPS teaching model also promotes the teacher's instructional design to reposition the teaching objectives and content, which helps to realize the two-way interaction between "teaching" and "learning", promotes teaching and learning, and students need to play the main role, teachers It plays a guiding role, making students' passive learning become active learning and ultimately achieving teaching results.

In the course of teaching, students should be encouraged to participate in "participatory learning” [7]. For example, the situational teaching method is divided into role-playing, so that students can be divided into small groups to carry out language practice in the context of nursing under the guidance of teachers. According to the classification of medical departments, students simulate the scenes of English communication between patients and nurses, nurses and doctors, and learn how to use correct and appropriate English expressions in real situations. In teaching, attention should be paid to the training of students' voice pronunciation and intonation. Guiding students to master phonetic knowledge is not only conducive to using correct pronunciation to express, but also conducive to the acquisition and improvement of listening skills. At the end of the class, the teacher asks the students to describe the content of the text by oral summary, or to summarize the knowledge of the lesson, in order to train the students 'English reading inductive ability and oral expression ability. Students are encouraged to communicate in English listening and speaking during nursing practice, and to combine their knowledge with practice so as to deepen their understanding, cognition and absorption of the language. 
The teacher divides the students into three equal or three-person groups and proposes discussion questions and topics related to the course. In group discussion, each group will focus on a certain topic. At this time, teachers need to grasp the direction of learning, pay attention to the learning dynamics of each group, provide targeted and individualized guidance for possible problems, maintain positive and effective interaction between teachers and students in the whole process, and guide students to acquire core knowledge through communication and feedback. After the group discussion is over, the group representatives are sent to the stage to summarize, or to debate between groups of topics. The teacher also arranges the lecture task in advance for the group, and arranges the relatively simple textbook content for the students, and asks the students to send representatives to the stage for display. Students can fully mobilize their subjective initiative through the collection of materials after the class, browsing the web, accessing the literature, and preparing for PPT production. They also cultivate students' self-learning ability and improve teamwork spirit. The participatory teaching method can mobilize the enthusiasm of students to participate, and also cultivates the team spirit of students, and trains students' ability to use language comprehensively [8].

In the post-assessment of the BOPPPS teaching mode, the teacher designed the test content for the teaching content of this lesson, and tested the student's score on the spot. A diversity and diversified assessment approach should be adopted. The exam content can include oral exams, written exams, and several aspects. Post-assessment can help teachers adjust the teaching content according to the students' grades and feedback. In the post-assessment process, the teacher should review the content of the difficult points based on the analysis of the "post-test" results of each group of students, and briefly summarize the knowledge points. High quality international nursing talents must have a high level of Comprehensive English proficiency. However, whether they have certain English writing ability and whether they can accurately express themselves in English is also the standard to measure the working level of nursing talents. The important link in the daily work of nurses is written records. For example, the registration of patients' admission and discharge, the formulation of nursing plans, and summary of patients' discharge. Therefore, English writing training for nursing records should be appropriately incorporated into the teaching of nursing English. Help students develop good habits of using words accurately, expressing norms and writing correctly. The written examination at the end of the semester should include the mastery of medical English vocabulary abbreviations, the translation between Chinese and English, and the writing of English cases.

The BOPPPS teaching model emphasizes the full participation and timely feedback of students. It promotes the transformation of the role of teachers. The "language educators" in the classroom center become the "guides" to guide students to carry out collaborative and problem-based learning. They always pay attention to the performance of students in the classroom, and get students' feedback information in time, and adjust the follow-up teaching accordingly.

\section{Conclusion}

In a word, the teaching of English for foreign-related nursing specialty should be based on the needs of nursing specialty, and the teaching goal should be to cultivate students' good language expression ability in the professional field. The ultimate goal of teaching is to make students fully grasp the knowledge and make them have the ability to use it. We need to change the traditional teaching mode and adopt a new BOPPPS teaching mode. This teaching mode conforms to the trend of English teaching reform for nursing specialty and can combine English learning with medical and nursing knowledge. In addition to enriching students' nursing and medical knowledge, it can promote students to participate in all aspects of learning, and improve students' ability of listening, speaking, reading and writing in the field of nursing. Through the discussion, induction, practice, review and summary of the teaching content, the students' practical ability, learning ability and the best learning effect can be achieved[8]. The BOPPPS teaching model can closely combine the training objectives of nursing English teaching in Chinese medicine colleges, break the traditional teacher-centered teaching mode, attract students' interest in learning, 
encourage students to participate in the teaching process, and promote students to deeply understand and master the knowledge they have learned. For the country, we have developed high-quality compound talents who are proficient in English and familiar with nursing.

\section{References}

[1]. Chen Xiaoxia, Chen Yuqing, Du Juan, Li Lizhen. Application of CGFNS Course in Nursing Teaching of Foreign Nursing Specialty [J]. International Journal of Nursing, 2010,10.

[2]. Yao Lijuan, Gao Xiaolian. Investigation and Analysis on the current situation of English teaching for foreign-related nursing specialty in Colleges and universities--Taking Hubei University of Traditional Chinese Medicine as an example [J].Journal of Guangxi University of Traditional Chinese Medicine, 2012,4(15).

[3]. Johnson J B. Instructional skills workshop handbook for participants[R]. Vancouver: ISW International Advisory Committee, 2006.

[4]. Qin Bowen, Wang Haiyan. Teaching Direction and Teaching Model of English for Foreign-related Nursing Specialty [J]. Nursing Practice and Research 2011, 8 (17).

[5]. Xiao Wen Li Zhuang Yan Yan. Exploration and Adjustment of Nursing English Teaching Methods [J]. General Nursing, 2011,21.

[6]. Wang Hui. On the English Teaching of Foreign-related Nursing in English[J]. Science \& Technology Information (Academic Edition), 2008, 23.

[7]. Pat Pattison, Russell Day. Instruction Skills Workshop (ISW) Handbook for Participants[M].Vancouver: The instruction skills workshop international advisory committee, 2006.

[8]. Brown H.D. principles of Language Learning and Teaching [M].Foreign Language Teaching and Research Press, 2002 : 227-228 